\title{
ENHANCEMENT OF ANTITUMOR ACTIVITY OF BLEOMYCIN BY BENZAMIDE IN VITRO AND IN VIVO
}

\author{
Hiromi Sakamoto, Hisae Kawamitsu, Masanao Miwa, Masaaki Terada \\ and TAKashi Sugimura \\ National Cancer Center Research Institute \\ 1-1 Tsukiji 5-Chome, Chuo-ku, Tokyo 104, Japan \\ (Received for publication December 3, 1982)
}

\begin{abstract}
The cytotoxic effects of bleomycin on HeLa cells in culture were enhanced by incubation of the cells with benzamide, a potent inhibitor of poly(ADP-ribose) polymerase, at concentrations at which benzamide alone did not show any cytotoxicity. Benzamide plus bleomycin display enhanced therapeutic effects against Ehrlich ascites tumor cells in vivo. On daily treatment with various doses of bleomycin plus benzamide for 10 days, mice with Ehrlich ascites tumors survived longer than mice on treatment with bleomycin alone.
\end{abstract}

Poly(ADP-ribose) polymerase is localized in the nucleus and catalyzes the formation of poly(ADPribose) from NAD. ${ }^{1 \sim 6)}$ The following recent evidence suggests that poly(ADP-ribose) is important in DNA repair. Exposure of the cells to DNA damaging agents resulted in increase in poly(ADP-ribose) polymerase activity. ${ }^{710)}$ Inhibitors of poly(ADP-ribose) polymerase prevented the rejoining of DNA strand breaks ${ }^{11)}$ and increased the lethal effects of DNA damaging agents on culture cells. ${ }^{11 \sim 15)}$ It was also suggested that poly(ADP-ribose) activated DNA ligase. ${ }^{16)}$

Bleomycin, an antibiotic produced by Streptomyces, has a potent antitumor activity and is widely used clinically. The antibiotic is known to induce strand breaks of DNA. ${ }^{17,18)}$

We recently found that $m$-aminobenzamide and benzamide, inhibitors of poly(ADP-ribose) polymerase, potentiated the antitumor activity of bleomycin in Ehrlich ascites tumor cells, as judged by the ratio of the total packed cell volume of treated groups to that of control group. ${ }^{19)}$ The present experiments were designed to evaluate the effects of benzamide on the cytotoxic effects of bleomycin on HeLa cells in vitro. Based on these in vitro results, we also studied the in vivo effect of benzamide on survival of bleomycin-treated mice bearing Ehrlich ascites tumors.

\section{Materials and Methods}

\section{Chemicals}

Benzamide was purchased from Tokyo Kasei Chemical Co., Tokyo, Japan. Bleomycin hydrochloride was obtained from Nippon Kayaku Co., Tokyo, Japan.

\section{In Vitro Effects}

HeLa cells were maintained in $\alpha$-medium supplemented with $10 \%$ calf serum under a humidified atmosphere of $5 \% \mathrm{CO}_{2}$ in air at $37^{\circ} \mathrm{C}$. The cells were seeded at 200 cells per 60 -mm dishes. Then 40 to 48 hours later the medium was replaced by fresh medium containing various concentrations of bleomycin and benzamide. After incubation of the cells for 2.5 hours with bleomycin and benzamide, the medium was replaced by fresh medium containing various concentrations of benzamide and incubation was continued for 7 to 8 days. The colonies formed were stained with Giemsa stain and the plating efficiency was determined. Survival of cells treated with a test compound was expressed as the plating efficiency as a percentage of that of control cells. 


\section{In Vivo Effects}

Male $\mathrm{CDF}_{1}$ mice weighing 20 to $25 \mathrm{~g}$ and male ICR mice weighing 30 to $35 \mathrm{~g}$ were purchased from Charles River Japan Inc., Atsugi, Kanagawa. They were maintained on basal diet (CE-2; CLEA Japan Inc., Tokyo). Ehrlich ascites tumor cells were maintained in ICR mice by intraperitoneal inoculation. For studies on the chemotherapeutic effects of drugs, Ehrlich ascites tumor cells were obtained from mice 7 days after inoculation. The cells were diluted to $5 \times 10^{6}$ cells $/ \mathrm{ml}$ with sterile phosphate buffered saline (PBS) (135 m NaCl, $2.7 \mathrm{~mm} \mathrm{KCl,} 5.3 \mathrm{~mm} \mathrm{Na}_{2} \mathrm{HPO}_{4}$ and $1.45 \mathrm{~mm} \mathrm{KH}_{2} \mathrm{PO}_{4}$ ) and $0.2 \mathrm{ml}$ of cell suspension containing $1 \times 10^{8}$ cells was injected intraperitoneally (i.p.) unless otherwise specified. Drugs were administered daily for 10 days starting 24 hours after inoculation of the cells. Bleomycin was dissolved in sterile PBS with or without benzamide, and was administered to mice in a total volume of $0.35 \mathrm{ml}$ per mouse in the morning between 10:00 a.m. and 12:00 noon (1st injection). A second injection of benzamide was given 3 to 4 hours after the 1st injection. All mice were weighed every other day until the end of the experiment. Control mice received PBS i.p. at the times when test animals were treated with drugs. The mean survival time was calculated from the day of tumor inoculation. The percentage increase in life span (ILS) was calculated as follows:

$$
\mathrm{ILS}=\frac{\text { mean survival time of treated group }}{\text { mean survival time of control group }} \times 100-100
$$

\section{Results}

In Vitro Effects of Bleomycin and Benzamide on Survival of HeLa Cells

Benzamide alone did not have any cytotoxic effect on HeLa cells at concentrations of up to $600 \mu \mathrm{g} /$ ml (Fig. 1). However, it significantly enhanced the cytotoxic effects of bleomycin. When HeLa cells were exposed to bleomycin in the presence of benzamide and then incubated continuously in the presence

Fig. 1. Effects of benzamide on cytotoxicity of bleomycin of HeLa cells.

HeLa cells were exposed to the indicated concentrations of benzamide in the absence () or presence of $10 \mu \mathrm{g} / \mathrm{ml}(\bigcirc)$ or $50 \mu \mathrm{g} / \mathrm{ml}(\triangle)$ of bleomycin for 2.5 hours, and then cultured with the same concentration of benzamide alone. Survival of cells was determined as described in the text. Points indicate the values obtained from mean colony counts from 5 replicate plates.

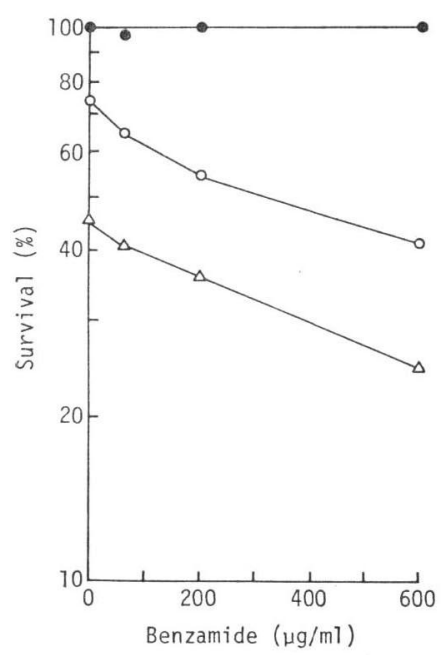

of various concentrations of benzamide, a dosedependent increase in cytotoxicity of benzamide was observed: Treatment of the cells with $10 \mu \mathrm{g} /$ $\mathrm{ml}$ of bleomycin plus $600 \mu \mathrm{g} / \mathrm{ml}$ of benzamide had the same cytotoxic effect as $50 \mu \mathrm{g} / \mathrm{ml}$ of bleomycin alone.

Fig. 2. Effects of bleomycin and benzamide on survival of mice bearing Ehrlich ascites tumors.

$\mathrm{CDF}_{1}$ mice bearing Ehrlich ascites tumors were treated with PBS (a), bleomycin at $4.7 \mathrm{mg} / \mathrm{kg}$ (b), benzamide at $137 \mathrm{mg} / \mathrm{kg}$ (c), bleomycin at $4.7 \mathrm{mg} /$ $\mathrm{kg}$ and benzamide at $137 \mathrm{mg} / \mathrm{kg}$ (d) as described in the text. Each group consisted of 6 mice.

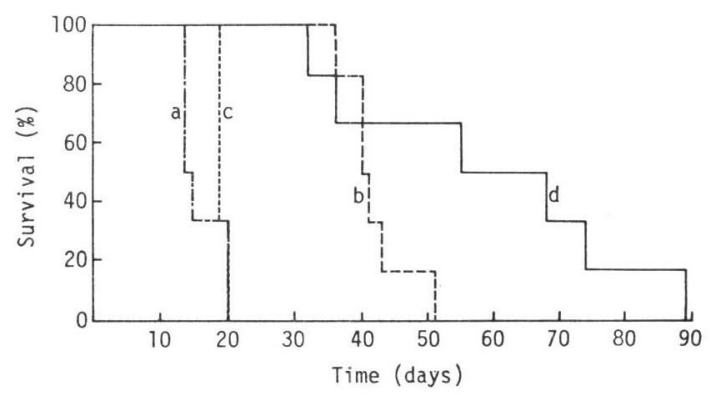


Effects of Treatments with Bleomycin plus Benzamide on Survival of

Tumor-bearing Mice

After intraperitoneal inoculation of $1 \times 10^{8}$ Ehrlich ascites tumor cells, the body weights of the mice increased as the tumor cells grew, and by Day 15 to 19, all the mice had died. Benzamide had no apparent toxic effect on mice when administered i.p. at a dose of $137 \mathrm{mg} / \mathrm{kg}$ twice daily for 10 days. It could not be administered at higher doses because of the insolubility. One or two daily i.p. injections of benzamide at $137 \mathrm{mg} / \mathrm{kg}$ given on Days 1 to 11 after tumor inoculation had no effect on survival of the mice (Table 1).

When given to tumor-bearing mice from Day 1 to 11 , bleomycin alone had a therapeutic effect. With daily doses of $1.7 \mathrm{mg} / \mathrm{kg}, 2.3 \mathrm{mg} / \mathrm{kg}, 4.7 \mathrm{mg} / \mathrm{kg}$ and $5.1 \mathrm{mg} / \mathrm{kg}$ of bleomycin, the ILS values were $28 \%, 47 \%, 158 \%$ and $80 \%$, respectively. Bleomycin also caused significant delay in tumor growth, manifested as delay in body weight gain (data not shown). However, on treatment with bleomycin alone, no mice survived longer than 60 days after inoculation of tumor cells.

The effects of combinations of various doses of bleomycin and benzamide given i.p. on Days 1 to 11 after tumor implantation were studied in 3 separate experiments. In all experiments, treatment of mice with bleomycin plus benzamide resulted in increase in the mean survival time. On treatment with bleomycin at $4.7 \mathrm{mg} / \mathrm{kg}$ plus benzamide at $137 \mathrm{mg} / \mathrm{kg}$, the ILS value was $264 \%$, whereas with the same dose of bleomycin alone the ILS value was $158 \%$. After combination therapy, 3 of 6 mice survived for longer than 60 days, whereas on treatment with bleomycin alone no mice survived for 60 days (Table 1 , experiment A; Fig. 2).

In an attempt to keep the level of benzamide in the body high, we injected bleomycin at $5.1 \mathrm{mg} / \mathrm{kg}$

Table 1. Effects of bleomycin and benzamide on Ehrlich ascites tumor cells in mice.

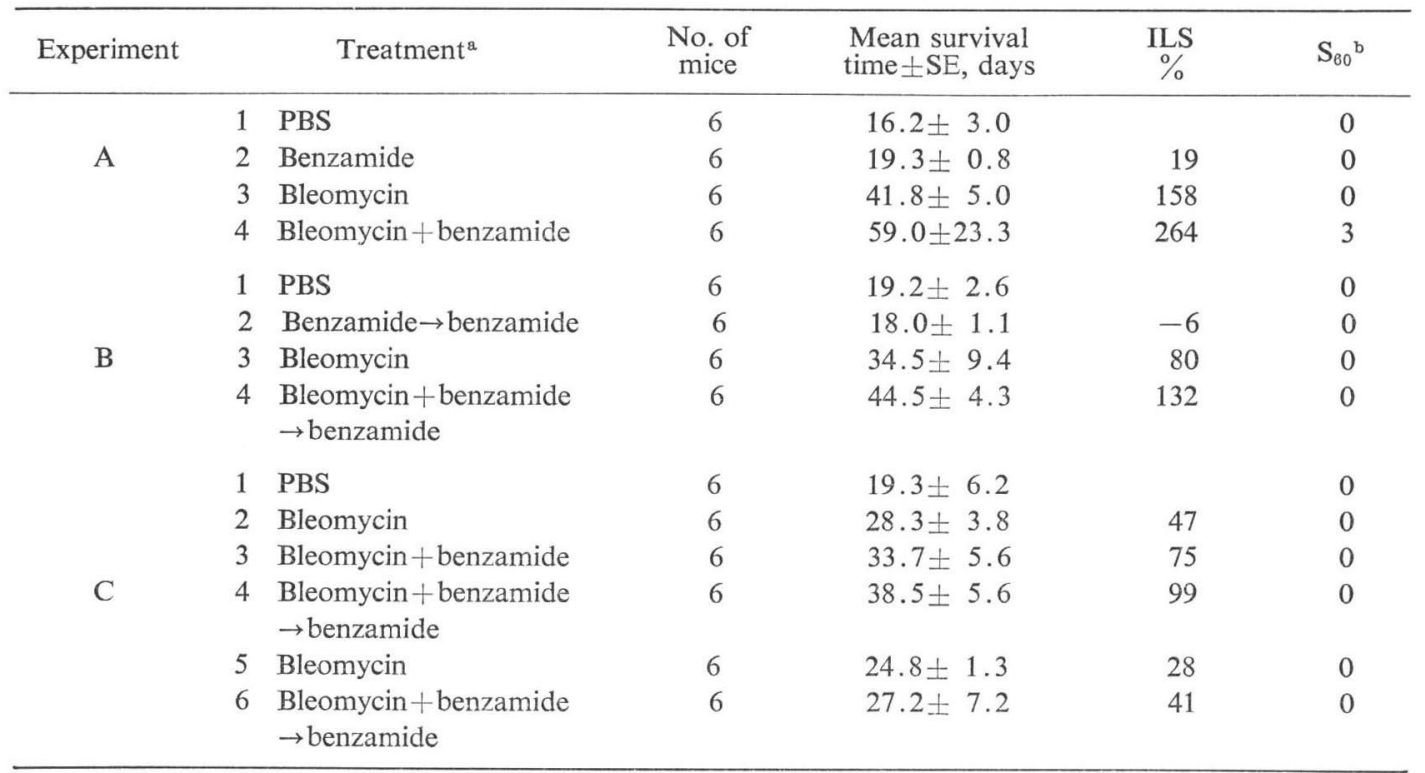

a In experiments $\mathrm{A}$ and $\mathrm{B}$, bleomycin was given i.p. at $4.7 \mathrm{mg} / \mathrm{kg}$ and $5.1 \mathrm{mg} / \mathrm{kg}$, respectively. In experiment $\mathrm{C}$, bleomycin was given at $2.3 \mathrm{mg} / \mathrm{kg}$ to groups 2,3 and 4 , and at $1.7 \mathrm{mg} / \mathrm{kg}$ to groups 5 and 6 . Benzamide at $137 \mathrm{mg} / \mathrm{kg}$ was administered once or twice daily in experiments $\mathrm{A}$ to $\mathrm{C}$. The arrow indicates a second injection of benzamide 3 to 4 hours after the first injection.

b $\mathrm{S}_{60}$; number of mice surviving more than 60 days after tumor inoculation. 
plus benzamide at $137 \mathrm{mg} / \mathrm{kg}$ first, and 3 to 4 hours later injected benzamide again at $137 \mathrm{mg} / \mathrm{kg}$ (Table 1 , experiment B). With bleomycin alone, the ILS value was $80 \%$ and with bleomycin plus two injections of benzamide, the ILS became $132 \%$, but benzamide alone had no effect on the survival of mice. On treatment with $2.3 \mathrm{mg} / \mathrm{kg}$ of bleomycin, the ILS of tumor-bearing mice was $47 \%$, whereas with $1.7 \mathrm{mg} / \mathrm{kg}$ of bleomycin the ILS was only $28 \%$ (Table 1 , experiment C). With bleomycin at $2.3 \mathrm{mg} / \mathrm{kg}$ and benzamide at $137 \mathrm{mg} / \mathrm{kg}$, the ILS was $75 \%$, while with bleomycin at the same doses plus benzamide, followed by a second injection of benzamide, the ILS value was $99 \%$. With doses of bleomycin as low as $1.7 \mathrm{mg} /$ $\mathrm{kg}$, benzamide had little effect on the mean survival time of mice.

\section{Discussion}

The present studies show that the cytotoxic effect of bleomycin on HeLa cells in culture was enhanced by benzamide, a potent inhibitor of poly(ADP-ribose) polymerase. ${ }^{20,21)}$ Similar enhancing effects of inhibitors of poly(ADP-ribose) polymerase on the cytotoxic action of bleomycin on L1210 cells in vitro have recently been reported. ${ }^{22}$

We have also shown that benzamide potentiated the therapeutic effect of bleomycin on Ehrlich ascites tumor cells in vivo. In all experiments with concentrations of bleomycin of $1.7 \mathrm{mg} / \mathrm{kg}$ to $5.1 \mathrm{mg} / \mathrm{kg}$, combination treatment with benzamide increased the mean survival time of mice over those of mice treated with bleomycin alone. Benzamide alone did not have any therapeutic effect against Ehrlich ascites tumor cells. With lower doses of bleomycin, the increase in survival time with combination therapy became less significant. From these results, it seems likely that benzamide exerted its cytotoxic effects on cells that had been damaged by bleomycin. It should be noted that only mice treated with bleomycin plus benzamide survived longer than 60 days after tumor inoculation.

The additional administration of benzamide 3 to 4 hours after injection of bleomycin plus benzamide resulted in increased survival of mice comparing with those given a single daily injection of bleomycin plus benzamide. This finding implies that benzamide will be more effective against Ehrlich ascites tumor cells when it is continuously infused after injection of bleomycin.

The following findings have suggested that poly(ADP-ribose) is involved in the process of DNA repair. Exposure of cells to DNA damaging agents lead to increased poly(ADP-ribose) polymerase activity with concomitant increase in the intracellular level of poly(ADP-ribose). ${ }^{7 \sim 10,20,21)}$ The intracellular level of NAD, which is used to make poly(ADP-ribose), was markedly reduced by treatments of cells that cause DNA damage. ${ }^{10,20,21,23 \sim 26)}$ Exposure of cells to alkylating agents followed by the culture with an inhibitor of poly(ADP-ribose) polymerase resulted in inhibition of rejoining of DNA strand breaks. ${ }^{11}$ Thus, the enhancing effect of benzamide on the cytotoxic action of bleomycin in vitro and in vivo is probably caused by inhibition of rejoining of DNA strand breaks caused by bleomycin.

\section{Acknowledgments}

This work was supported in part by Grants-in-Aid from the Ministry of Health and Welfare, the Ministry of Education, Science and Culture of Japan and the Princess Takamatsu Cancer Research Fund.

\section{References}

1) Chambon, P.; J. D. Weill, J. Doly, M. T. Strosser \& P. Mandel: On the formation of a novel adenylic compound by enzymatic extracts of liver nuclei. Biochem. Biophys. Res. Commun. 25: 638 643, 1966

2) Fujimura, S.; S. Hasegawa \& T. Sugimura: Nicotinamide mononucleotide-dependent incorporation of ATP into acid-insoluble material in rat liver nuclei preparation. Biochim. Biophys. Acta 134: 496 499, 1967

3) Nishizuka, Y.; K. Ueda, K. Nakazawa \& O. HaYaishi: Studies on the polymer of adenosine diphosphate ribose. 1. Enzymic formation from nicotinamide adenine dinucleotide in mammalian nuclei. J. Biol. Chem. 242: 3164 3171, 1967 
4) Sugimura, T.: Poly(adenosine diphosphate ribose). Prog. Nucleic Acid Res. Molec. Biol. 13: 127 151, 1973

5) Hayaishi, O. \& K. Ueda: Poly(ADP-ribose) and ADP-ribosylation of proteins. Annu. Rev. Biochem. 46: $95 \sim 116,1977$

6) Thraves, P. \& M. Smulson: Poly(ADP-ribose) and DNA repair, studies on polynucleosomal level of chromatin. In A. T. Natarajan, G. Obe \& H. Altman Eds., Progress in Mutation Research, Vol. 4, pp. 147 166, Elsevier Biomedical, Amsterdam, 1982

7) Miller, E. G.: Stimulation of poly(adenosine diphosphate-ribose) polymerase activity by bleomycin. Fed. Proc. 36: 906, 1977

8) Berger, N. A.; G. W. Sikorski, S. J. Petzold \& K. K. Kurohara: Association of poly(adenosine diphosphoribose) synthesis with DNA damage and repair in normal human lymphocytes. J. Clin. Invest. 63: $1164 \sim 1171,1979$

9) Benjamin, R. C. \& D. M. Gill: ADP-ribosylation in mammalian cell ghosts: Dependence of poly(ADPribose) synthesis on strand breakage in DNA. J. Biol. Chem. 255: 10493 10501, 1980

10) Jacobson, M. K.; V. Levi, H. Juarez-Salinas, R. A. Barton \& E. L. Jacobson: Effect of carcinogenic $N-$ alkyl- $N$-nitroso compounds on nicotinamide adenine dinucleotide metabolism. Cancer Res. 40: 1797 1802,1980

11) Durkacz, B. W.; O. Omidiu, D. A. Gray \& S. Shall: (ADP-ribose) participates in DNA excision repair. Nature 283: $593 \sim 596,1980$

12) Nduka, N.; C. J. Skidmore \& S. Shall: The enhancement of cytotoxicity of $N$-methyl- $N$-nitrosourea and of $\gamma$-radiation by inhibitors of poly(ADP-ribose) polymerase. Eur. J. Biochem. 105: 525 530, 1980

13) Durkacz, B. W.; J. Irwin \& S. Shall: The effect of inhibition of (ADP-ribose) ${ }_{n}$ biosynthesis on DNA repair assayed by the nucleoid technique. Eur. J. Biochem. 121: 65 69, 1981

14) Gray, D. A.; B. W. Durkacz \& S. Shall: Inhibitors of nuclear ADP-ribosyl transferase retard DNA repair after $N$-methyl- $N$-nitroso-urea: Further evidence for the involvement of (ADP-ribose) ${ }_{n}$ in DNA repair. FEBS Lett. 131: 173 177, 1981

15) Durrant, L. G. \& J. M. Boyle: Potentiation of cell killing by inhibitors of poly(ADP-ribose) polymerase in four rodent cell lines exposed to $N$-methyl- $N$-nitrosourea or ultraviolet light. Chem. Biol. Interactions 38: $325 \sim 338,1982$

16) Creissen, D. \& S. Shall: Regulation of DNA ligase activity by poly(ADP-ribose). Nature 296: 271 272,1982

17) Umezawa, H.; M. Ishizuka, K. Maeda \& T. Takeuchi: Studies on bleomycin. Cancer 20: 891 895, 1967

18) Bishun, N. P.; N. S. Smith \& D. C. Williams: Bleomycin (Review). Oncology 35: 228 234, 1978

19) Kawamitsu, H.; M. Miwa, Y. Tanaka, H. Sakamoto, M. Terada, A. Hoshi \& T. Sugimura: Inhibitors of poly(adenosine diphosphate ribose) polymerase potentiate the antitumor activity of bleomycin against Ehrlich ascites carcinoma. J. Pharm. Dyn. 5: 900 904, 1982

20) Juarez-Salinas, H.; J. L. Sims \& M. K. Jacobson: Poly(ADP-ribose) levels in carcinogen-treated cells. Nature 282: $740 \sim 741,1979$

21) Sims, J. L.; G. W. Sikorski, D. M. Catino, S. J. Berger \& N. A. Berger: Poly(adenosine diphosphoribose) polymerase inhibitors stimulate unscheduled deoxyribonucleic acid synthesis in normal human lymphocytes. Biochemistry 31: 1813 1821, 1982

22) Fukushima, M.; T. Kato \& K. OHtA: Enhancement of cytotoxic action of bleomycin by inhibitors of poly(ADP-ribose) synthesis. Proceedings of 13th Int. Cancer Cong., p. 34, Washington, 1982

23) Skidmore, C. J.; M. I. Davies, P. M. Goodwin, H. Halldorsson, P. J. Lewis, S. Shall \& A-A. Zia'ee: The involvement of poly(ADP-ribose) polymerase in the degradation of NAD caused by $\gamma$-radiation and $N$-methyl- $N$-nitrosourea. Eur. J. Biochem. 101: 135 142, 1979

24) Berger, N. A.; G. W. Sikorski, S. J. Petzold \& K. K. Kurohara: Defective poly(adenosine diphosphoribose) synthesis in xeroderma pigmentosum. Biochemistry 19: 289 293, 1980

25) Rankin, P. W.; M. K. Jacobson, V. R. Mitchell \& D. L. Busbee: Reduction of nicotinamide adenine dinucleotide levels by ultimate carcinogens in human lymphocytes. Cancer Res. 40: 1803 1807, 1980

26) MCCurry, L. S. \& M. K. JACobson: Poly(ADP-ribose) synthesis following DNA damage in cells heterozygous or homozygous for the xeroderma pigmentosum genotype. J. Biol. Chem. 256: 551 553, 1981 